\title{
ARIKI TAPATI RAPA NUI - REINAS DE LA TAPATI RAPA NUI: ANÁLISIS DE UN DISPOSITIVO FESTIVO Y GENÉRICO
}

\author{
Ariki Tapati Rapa Nui-Queens of Tapati Rapa Nui: analysis of a festive and gendered \\ device
}

THÉO MILIN*

Fecha de recepción: 19 de abril de 2020 - Fecha de aprobación: 24 de octubre de 2020

\section{Resumen}

Este artículo aborda el festival cultural de la Tapati Rapa Nui desde su figura "clave", la reina, o ariki Tapati. Consideramos aquí la elección de la reina como un "dispositivo festivo" adoptado por la comunidad rapanui que ha ido cambiado según propuestas identitarias y culturales. Por lo tanto, la reina es una figura que, por sus tensiones, desarrollo y continuidades, nos habla, en filigrana, de una trayectoria de rapanuización. Ella surge después de un proceso ritual, dinámico y cambiante, que desarrolla mecanismos propios del grupo, los cuales participan en su reproducción social. Al pasar por este proceso, combinando trabajo comunitario ('umana) y competencia ('a'ati), la reina se encuentra sometida a varias limitaciones y obligaciones. También adquiere prerrogativas y un poder de representación al convertirse en "el rostro de la comunidad".

Palabras claves: identidad; elección de reina; apropiación creativa; puesta en escena.

\section{Abstract}

This paper discusses the cultural festival Tapati Rapa Nui, and more specifically its figurehead, the elected "queen" (or ariki) of Tapati. It considers the queen pageant a "festive device", adopted by the Rapanui community, and evolving through cultural and identity dynamics. The queen is a figure whose tensions, evolutions and continuities describe an underlying trajectory of "rapanuization". She emerges at the end of a complex and changing ritual process, where mechanisms specific to the group are deployed, while also assuring its social reproduction. Upon accomplishing the rituals of Tapati Rapa Nui, combining community work ('umana) and competition ('a'ati), the queen finds herself subject to certain constraints and limitations. But she also acquires prerogatives and representative power, becoming the "face of the community".

Keywords: identity; pageant contest; creative appropriation; performance.

\footnotetext{
* Magíster en Ciencias Sociales, mención Relaciones Internacionales, Mondializaciones y Intercutluralidad. Doctorando en antropología / Univ Rennes 2, equipo ERIMIT (UR 4327), Francia. El artículo está enmarcado en la investigación doctoral en curso: "Rituales profanos de la «reina de la fiesta». Re-inventos polifacéticos de una coronación simbólica: redefiniciones de identidades colectivas y relaciones de género." Correo-e: milin.theo@laposte.net
} 


\section{Introducción}

En Rapa Nui, isla ubicada al extremo este del llamado "triángulo polinésico"1 en el Pacífico Sur, se da, desde hace más de cincuenta años, un ritual festivo singular, la Tapati Rapa Nui, que termina cada año con la coronación de una reina, llamada ariki Tapati ${ }^{2}$. Esta festividad ha ido tomando fuerza desde su inicio en el año 1968 y hoy en día se expresa bajo la forma de un festival cultural celebrado en febrero durante dos semanas. Durante sus quince días tiene lugar un amplio abanico de actividades que, siguiendo la topología establecida por Pablo Andrade (2004), se pueden dividir entre actividades deportivas, artísticas y productivas (aunque estas dimensiones se entremezclan). En ese intervalo, dos (o más) alianzas compiten en cada actividad para elegir a su candidata. La fiesta se percibe como un escenario que permite una gran y holística expresión de las artes y tradiciones de la isla.

El tema de la Tapati ha sido objeto de estudios previos en razón de su relevancia en una isla polinésica bajo soberanía chilena (desde 1888), donde el turismo se ha vuelto la fuente principal de ingresos para sus habitantes. Estos estudios abordan la Tapati desde su papel de reproducción social puesto que sus actividades permiten activar prácticas y mecanismos desde la comunidad: se trata de un ejercicio de reactivación de lugares, historias y costumbres bajo la forma de una perfomance (Andrade, 2004). La Tapati se construye también como una "zona de contacto" que articula a la isla con ámbitos locales, nacionales y regionales (Bendrups, 2008; Delsing, 2017) o como un elemento del proceso de patrimonialización que se está desarrollando en la isla (Concha, 2017). Sin embargo, dentro de estos estudios poco se ha dicho de la ariki Tapati, figura presente desde el inicio de la fiesta. Su elección constituye un pilar de esta celebración y permite dar cuenta de las orientaciones diversas que fue tomando. Por estas razones, este artículo se propone abordar la especificidad de la modalidad festiva de las elecciones de reinas en el caso de la Tapati.

Consideramos aquí las fiestas como "ventanas antropológicas privilegiadas", que permiten dar cuenta de aspectos culturales y étnicos "difícilmente aprehensibles por otras vías" (Fernández \& Venegas, 2010, p. 117). La fiesta hace, efectivamente, aparecer en un espacio-tiempo reducido un conjunto de símbolos, prácticas, imágenes, colores y sonidos. Dentro de estas "ventanas", las elecciones de reinas constituyen un "dispositivo festivo"3 específico que, a través de la coronación simbólica de una soberana, organiza una puesta en escena de una femineidad peculiar.

Por otra parte, la reina elegida, por sus características, encarna valores específicos del grupo. Es más, su encarnación y su proceso de emergencia, expuestos frente a un público, permiten, en un doble movimiento, "dar a ver el poder" y exprimir conceptos y prácticas destacadas por el grupo (Bellerino, Wilk \& Stoeltje, 1996, p. 3). Por lo tanto, el significado de la elección solamente puede ser entendido desde el grupo mismo (en eso, la reina actúa como un "signo") (Stoeltje, 1996). Difundido en el mundo entero, el fenómeno de las elecciones de reinas en Rapa Nui se debe entender dentro de un contexto nacional chileno y regional polinésico, donde abundan dispositivos similares.

Este artículo se basa en el trabajo efectuado en el marco de una tesina de magíster realizada 
entre los años 2017 y 2018. A eso, se añaden los datos recolectados en la investigación doctoral, empezada en 2019. Estos estudios consideran una vertiente etnográfica, compuesta de dos observaciones participantes en la Tapati de 2018 y 2020 . El tiempo en la isla, que también abarca otro terreno efectuado en 2019, sirvió para entrevistar a reinas, candidatas y actores de esta festividad. Por otro lado, el artículo se sustenta en una revisión de archivos y en un trabajo en hemeroteca (realizado esencialmente en los archivos de prensa del Museo Antropológico Padre Sebastián Englert, MAPSE).

Este escrito considerará la reina y su transformación como una emanación de la comunidad y una respuesta a sus problemáticas. ¿Cómo leer, entonces, la figura actual de la reina y sus cambios? Su evolución indica la conformación de una definición rapanui de la corona. Nos proponemos ver esta figura desde las características de su proceso de candidatura, elección y reinado. Consideraremos su elección como un elemento que permite la construcción de un "ser rapanui" distintivo y en interacción, un corpus en constante actualización que va definiendo la pertenencia y el manejo del grupo.

La reina se convirtió en un "emblema identitario" y actúa como la encarnación de un contenido que, siguiendo a Barth (1976), se constituye mediante la instauración de señales manifiestas, como son "el vestido, el lenguaje, la forma de vivienda o un general modo de vida", y de la indicación de orientaciones de valores básicos, es decir "las normas de moralidad y excelencia por las que se juzga la actuación" (p. 16). Este contenido, que hoy en día se cree y se piensa como propio de los rapanui, adquiere toda su substancia en la interacción con otros contenidos, tanto en el sentido de la semejanza que de la diferenciación. La figura de la reina (y la Tapati) tiene relevancia en este proceso generativo e interactivo de conformación de una etnicidad rapanui. En ese sentido, es una persona constantemente en "la frontera", entre su grupo y lo exterior (nacional, regional e internacional).

En primer lugar, se efectuará una descripción del desarrollo ritual de la Tapati, con sus significativas variaciones históricas. Segundo, veremos la integración de la candidatura y de la elección dentro de la comunidad, analizando los procesos que se activan con esa encarnación. Por último, se considerará la reina coronada "en la interacción", es decir, en sus funciones de mediación y de representación con los exteriores de la isla y como un elemento prominente del renuevo cultural rapanui, una expresión privilegiada de la cultura viva de la isla (término que usa la comunidad para referirse a su patrimonio inmaterial) (Muñoz, 2017).

\section{De la Tapati y su reina: antecedentes históricos y aparición}

La figura de la reina procede de un entrechoque de "piezas" agenciadas según la contingencia, más que del resultado de una mezcla cultural fácilmente identificable. Trazar una genealogía de la Tapati implica reconocer la encrucijada en la cual se encuentra ese dispositivo festivo, que, al igual que todas las fiestas, se presenta como un "mosaico". Se distinguen rasgos posiblemente provenientes de antiguas ceremonias, como el Tanata Manu o las competiciones de cantos (koro hakaopo) (Englert, 1974; Pakarati, 2016), que podrían considerarse hoy como "juegos" o "competencias". 
Según interpretaciones arqueológicas de estas fiestas, con ellas se organizaba una distribución del poder. Se identifican, además, conexiones con celebraciones del período del contacto, a veces trágico, con el exterior (barcos de las Américas o de Europa) y su posterior anexión por parte de Chile, como los Miro'o'one o las fiestas "carnavalescas" descritas por Métraux en 1935 (Delsing, 2017; Métraux, 1941; Pakarati, 2016). Este calificativo resulta llamativo porque traduce cierto bullicio y desorden aparente percibido por el autor suizo $y$, por lo mismo, algo de incomprensión del sentido del evento.

Más contemporánea, y directamente heredada del colonialismo chileno, es la Fiesta de la Primavera. Nace en 1910 en Valparaíso, dentro de la alta sociedad aristocrática y letrada. Los estudiantes de aquella época la adoptaron rápidamente y no tardó en difundirse a lo largo del país. Tuvo una fácil asimilación por parte de las élites provinciales, ansiosas de adoptar el "modo de ser" aristocrático santiaguino. Como fiesta cívica, se volvió un vector de la "chilenidad" y una "industria de Estado", como lo son varias fiestas de reinas alrededor del mundo (Deshoullière \& Dziubinska, 2017, p. 13).

Rápidamente se instaló dentro de un repertorio "tradicional" (Hobsbawm \& Ranger, 2012), incentivada por el poder político por su "sana alegría" (entender su "inocuidad"). Se refleja en ella la "fiesta civilizatoria", que tiene que reemplazar a las fiestas populares, chayas, carnavales, vistas como "desmanes" (Espinosa, 2013). Desde esta óptica, la reina encarna la "pureza" y la "elegancia" y, al mismo tiempo, la "renovación", perceptible en el término "Flor Natural" que la designa. Junto con su pareja (el ganador del concurso de poesía), simbo- lizan implícitamente el progreso de la "raza" y la civilización de la nación (De la Luz Hurtado, 2008). En esa fiesta encontramos los elementos que serán la base histórica de la Tapati: una reina, elegida por venta de votos, que desfila en su carro y sube vestida de blanco a un trono floreado, rodeada de su corte, donde se le ofrece una velada artística.

La Tapati nace de la conjunción de varios procesos, que hacen de ella un dispositivo festivo idóneo en un momento histórico preciso. En primera instancia, cabe mencionar los eventos del período 1964-1967, tras los cuales la población rapanui accedió a la ciudadanía chilena y a los derechos civiles y políticos asociados. Antes de esa fecha, el pueblo rapanui estaba bajo un orden colonial, expuesto a múltiples atropellos y crímenes, tanto por parte de la Compañía Explotadora de la Isla de Pascua (CEDIP) 4 como de la Armada chilena (Comisión Verdad Histórica y Nuevo Trato con los Pueblos Indígenas, 2008). En un contexto internacional y nacional específico ${ }^{5}$, la comunidad rapanui inició una sublevación a fines de 1964, liderada por su élite intelectual y política (de la cual el profesor Alfonso Rapu será la figura principal), contra la gestión militar y abusiva ejercida por la Armada chilena en la isla. La rebelión consiguió, después de un período de lucha, obtener una igualdad formal para la isla, reconocida a través de la "Ley Pascua" en 1966.

Con ello se levantó la restricción de circulación establecida alrededor de Hanga Roa (principal aglomeración urbana de la isla) y se otorgaron los derechos civiles correspondientes. Poco después llegaron a la isla los servicios públicos, con sus funcionarios: carabineros, posta y diversas instituciones públicas. Ese despliegue del Estado, a través de sus "brazos actuantes", 
que son las instituciones públicas, tuvo cierta influencia en la emergencia de la Tapati. Hanga Roa tomó, a partir de ese momento, la dirección de un desarrollo urbano intenso que la llevó, años después, a su transformación en la ciudad cosmopolita que conocemos hoy, compuesta de hoteles, tiendas, cafés, etc. (Fischer, 2005).

Otro hito importante en la emergencia de la Tapati es la apertura, en 1967, de la pista de aterrizaje en Mataveri y la instauración consecutiva de vuelos comerciales desde Chile. Esto fue el inicio de un flujo creciente de turistas en la isla, lo cual modificó su economía hacia una de servicios y cambió la estructura de la sociedad (composición interna de la población, características socioeconómicas, etc.). La llegada siempre más regular y masiva de turistas tuvo fuerte incidencia sobre la Tapati y su reina.

Fue también en 1967 que emergió la idea de crear una celebración en la isla. El modelo que se adoptó fue el de la Fiesta de la Primavera que se celebraba en Chile continental. Una celebración cívica, cuyo papel sería el de entretener a las personas de la isla y, al mismo tiempo, hacer visibles a los nuevos actores públicos y levantar una puesta en escena para los turistas. Como lo indica la guía del visitante de 1990, la creación se enmarcó dentro de un incentivo del gobierno "que instruía a las Gobernaciones Provinciales de todo el país a conmemorar dicha celebración con el propósito de aportar a las comunidades una sana entretención al darle la bienvenida popular a la Primavera en torno a festejos sociales y la elección de una reina" (llustre Municipalidad de Isla de Pascua, 1990).

Delsing y Fischer subrayan otro posible origen de la Tapati y de sus elecciones de reinas. La idea provendría de Florencia Atan Hotus y su familia, quienes se inspiraron en el festival Tiura'i en Papeete, al cual ella asistió (Delsing, 2017, p. 213; Fischer, 2005). Por supuesto, los dos relatos no son excluyentes entre sí y ponen de relieve, nuevamente, esa encrucijada permanente de la Tapati y de su reina entre la reivindicación del espacio polinésico y la presencia de un espacio nacional chileno. Esta dialéctica, que ejemplificaremos más adelante, tiende a destacar señales polinésicas (en los objetos, los colores, las palabras), que actúan como emblemas de diferencia, frente a otras, pasadas por alto.

\section{El camino de una candidata hasta la corona en la Tapati Rapa Nui: transformaciones históricas}

\section{"Subirse": condiciones y contextos de candidaturas}

Detallaremos aquí el proceso del dispositivo festivo. Es en esta parte que se pueden encontrar similitudes con elecciones de reinas en otros lugares. La secuencia "candidatura preparación - elección - coronación - reinado" se mantiene idéntica en la mayoría de los dispositivos de elecciones. El primer paso, la candidatura, sitúa a la postulante en un proceso intenso, a veces rudo, en el cual se enfrenta a numerosas obligaciones, recomendaciones y solicitaciones.

Originalmente, lo que buscaba la Tapati en términos de perfil era una mujer rapanui joven, con un estatuto premarital. La conexión simbólica entre reproducción biológica y social que instalan las elecciones de reinas es bastante patente. Ese tropo de la virginidad, la pureza, claramente existente en la Fiesta de la Prima- 
vera, también se hace presente en la Tapati. Una candidata no puede tener hijo(a) ni estar casada; el noviazgo está autorizado, lo que muestra que se trata más de la búsqueda de un estatuto social específico que de una estricta búsqueda de un supuesto "estado físico" de virginidad. El rango de edad necesario para ser candidata demuestra esa condición: si actualmente la edad está fijada en un mínimo de 18 años, no siempre fue así: aparecen reinas elegidas con 14, 15 o 16 años. Al ser menor de edad, era costumbre pedir un acuerdo firmado por el padre o, eventualmente, la madre. Con el tiempo, las uka ("postulantes") tuvieron una edad más avanzada e incluso se llegó a aceptar, excepcionalmente, a una candidata de más de 25 años $^{6}$.

En cuanto a la iniciativa de la candidatura, en las primeras ediciones, cuando la presencia de la Fiesta de la Primavera era más perceptible, era común que el(la) alcalde(sa) o alguna institución pública de la isla solicitara una candidatura a los padres de la joven:

La verdad, la alcaldesa Lucía Tuki Make, necesitaba candidatas para su fiesta. Nadie quería ser candidata, porque en mi tiempo, todas las niñas tienen vergüenza, no quieren participar. Entonces, la alcaldesa fue a ver a mi papá, diciendo "quiero una de tus flores como candidata", iporque mi papá con mi mamá tenían 7 niñas! [...] Yo era mayor, entonces me dijeron: "tú vas a ser candidata". "Ah, ya, bueno" dije. De primera, no quise presentarme, sino que me pidieron. (Entrevista Claudia González Pakarati, 2020)

Conforme pasaron los años, las dinámicas que regían el proceso de candidatura fueron cambiando. La iniciativa de la candidatura se traslada a la familia, que se reúne y lo decide. Esto, a veces, sin avisar de antemano a la interesada:
En ese tiempo mi madre [Analola Tuki Chávez] trabajaba en el hospital y, sin saber yo, fue a inscribirme [risas]. Después yo fui avisar a ella, porque no era perfecto para poder competir, porque yo era menor de edad. Era posible, pero tenía que autorizar mi mamá, y firmar un papel para poder ser candidata. [...] Da igual mamá o papá. (Entrevista Denisse Rapu Tuki, 2020)

Otras veces la candidatura se decide en circunstancias especiales, como promesa hacia un familiar particularmente cercano (Entrevista Lucy Haoa Tuki, 2020). En todas estas modalidades, varias son las reinas que reconocen no haber elegido asumir el cargo, incluso algunas mencionan su descontento por estar inscritas; pero muy pocas veces pudieron intervenir sobre la decisión tomada. Esto remite a la estructuración jerárquica de la sociedad rapanui, que es, ante todo, una jerarquía generacional (McCall, 1998; Muñoz, 2014).

La etapa siguiente es la búsqueda de un(a) apoderado(a) (y durante un tiempo, de una institución pública) para "patrocinar" la candidatura. Durante años, el criterio para elegir al apoderado fue económico: se buscaba a personas de fortuna (dueños de establecimientos, empresarios chilenos y algunos rapanui), capaces de sustentar el costo de la preparación y de la fiesta para la familia. Así, Ana Tucki Hucke (1975) tuvo como apoderado al dueño de la discoteca Piriti, mientras que Denisse Rapu Tuki (1981) contó con el apoyo de la esposa del dueño de la Empresa Nacional del Petróleo (ENAP) en la isla ${ }^{7}$.

En un período ulterior, el sistema de apoderados dejó de descansar en el único criterio del poder económico para fomentar el reconocimiento por la comunidad de la persona, en relación con su conocimiento cultural y de la 
Tapati misma, además de su proximidad con la candidata. Como resultado, a partir de la década de 1990, la totalidad de los(as) apoderados(as) resulta ser rapanui. El patrocinio por empresarios foráneos queda vigente, pero se ejecuta a través de la Municipalidad, que se instala paulatinamente como el principal organizador desde 1974, fecha a partir de la cual la Gobernación deja el cargo.

\section{Aprendizaje y preparación}

Al momento de asumir la candidatura, empieza el proceso de preparación. Esto significa que la candidata entra en un ciclo de aprendizaje intenso, donde tiene que entrenarse para las diferentes etapas de la festividad: bailes, cantos, pero también discursos, actitud y postura en el escenario. El dispositivo de la elección exige una cierta "disciplina" de la candidata, tanto corporal como mental. Varias siguen una preparación física especial durante los meses anteriores a la Tapati, mientras que algunas se forman para "desenvolverse en el escenario". Otro ejercicio es la promoción de sus candidaturas, en los medios locales, regionales $y$, a veces, nacionales, o en eventos festivos en discotecas y locales de la isla.

La parte más importante del aprendizaje se enfoca en la maestría del repertorio cultural que deberá ejecutar la candidata durante dos semanas. Es la ocasión para que ella pueda profundizar en sus conocimientos sobre los saberes tradicionales, con lo que se reactiva la circulación oral (te mo 'a) intergeneracional. En esa etapa, la candidata visita a maestros(as) y estudiosos(as) de la cultura, las nua, y los koro ("abuelas y abuelos") de su familia.
Es así que nos encontramos frente a discursos divergentes: algunas candidatas sostienen que no fue tan difícil la preparación debido a una inmersión en las artes y prácticas desde niña. En esa óptica, podríamos sostener que la preparación no inicia con la candidatura: se empieza a través de la participación en conjuntos folklóricos, verdadera espina dorsal del contenido artístico de la Tapati desde sus inicios, o en las precedentes Tapati: "Siempre tuve una participación, no me pierdo ni una Tapati [...] en lo que sea, apoyar, competir, siempre está en mis planes la Tapati” (Entrevista Mae‘ha León Durán, 2020). O simplemente en la familia misma, que a veces anda preparando una candidatura años antes, o que puede tener una "tradición de reinas" en su seno, lo que facilita bastante las cosas (es el caso de la familia Rapu, de donde salieron un gran número de reinas).

Por el contrario, otras candidatas cuentan vivencias diferentes en cuanto a la dificultad de la preparación:

Tuve que tomarme un tiempo récord para aprender el vānana, no es que no entienda, pero el hablar es distinto. Entiendo cuando hablan, pero cuando conjugan las frases es complicado, una palabra puede significar diferentes cosas, entonces eso ha sido uno de los aprendizajes "maratón" que tuve. También aprender a hacer kaikai, sabía lo simple, pero esta vez hice un kaikai súper largo. (Entrevista Waitiare Kaltnegger Icka, 2018)

Esto está relacionado con las circunstancias variables en las cuales se desarrollan las preparaciones. Waitiare tuvo que entrar como candidata dos meses antes del inicio de la Tapati, por lo que contó con un tiempo de preparación más corto de lo habitual. Se añaden sus dificultades con el vānana rapanui (nombre del idioma 
vernáculo) por el hecho que Waitiare pasó parte de su juventud fuera de la isla. Por lo general, la preparación es recordada como un período intenso, pero necesario para asumir las dos semanas de competencias y actividades de la Tapati Rapa Nui.

\section{Participación y elección}

A lo largo de los años, la modalidad de elección conoció significativas variaciones. En un primer período (1967-1985), la elección se realizó con escrutinio, a través de la venta de votos (e in fine a través del dinero) y la ronda de preguntas a las candidatas, el mismo sistema bajo el cual funcionaba en la Fiesta de la Primavera de Chile continental. Las otras pruebas (atletismo, fútbol, etc.), tenían una menor incidencia en la elección misma. En el segundo sistema, el de los años ochenta en adelante, las elecciones funcionaron con un sistema mixto de votación y pruebas con puntaje. Cuando Rodrigo Paoa ("el profesor") asume como coordinador general de la Tapati en 1985 cambia la naturaleza de las pruebas con la introducción de los deportes autóctonos $^{8}$. El tercero y actual sistema de elección, implementado desde mediados de los noventa, descansa en un conteo complejo de las pruebas dadas por las alianzas. En 2013, se incorporó una última novedad con la elección del aito, un "acompañante". Vemos que, al mismo tiempo que aumenta la complejidad del modo de elección, la Tapati se hace también más competitiva.

Las modificaciones en la modalidad de elección conllevan un cambio en el protago- nismo de la candidata y en su participación creciente en las pruebas. Si bien desde el inicio de la fiesta la reina tiene un papel relevante, en las danzas, los cantos o al ejecutar, por ejemplo, una canción original frente al público y el jurado (compuesto en parte por turistas/ visitantes), su protagonismo no iba mucho más allá de estas representaciones:

En nuestra época, las candidatas no hacían competencias... Había jóvenes que lo hacían para mí [...] Sí tuve que aprender un kaikai, un juego de hilo, pero fue lo único que tuve que presentar. Pero en general, nosotras estábamos sentadas, y sí, ¡no hacíamos mucho! [risas] Hoy en día las chicas participan más en las competencias, sí, pero antes no... Estaba elegida como candidata y tenía que tener la gente trabajando para mí. Solo era el rostro del clan. (Entrevista Elena Angélica Varas Edmunds, 2019, traducido desde el francés)

Con el tiempo, la gama de competencias exigidas va aumentando y hoy en día una candidata tiene que ser capaz de rendir pruebas deportivas, de confeccionar collares y coronas de flores, de realizar kaikai y takona recitando los pata'uta'u y, obviamente, de bailar y cantar. Así, la reina, con un protagonismo renovado, participa en un "hacer cultura" general desplegado durante la Tapati. Desde ahí, al igual que todos y todas las participantes, toma parte en la perpetuación, la recreación y la reactualización de los mitos, historias y prácticas ${ }^{9}$ que sostiene la fiesta. La especificidad de la elección de la ariki Tapati es su participación, de múltiples formas, en la construcción de "lo rapanui", que se hace mediante las manifestaciones artísticas y estéticas, pero no únicamente. 
La candidata y la reina, vector de un "ser rapanui" y de mecanismos propios del grupo

\section{La influencia del modelo continental de reina en la construcción de la ariki Tapati}

La reina encarna la (re)construcción étnica hecha por los isleños e isleñas. Esta, altamente fluida en cuanto a su contenido, se posiciona ante todo como distintiva de una "chilenidad", construcción identitaria homogeneizante avatar de una cultura hegemónica promovida por el Estado-nación chileno a través de sus fiestas cívicas. Sin embargo, los relatos de las primeras Tapati muestran que no siempre fue tan explícita esa adscripción alternativa en la fiesta. Primero, por el hecho que los objetivos de la Tapati y de la elección eran diferentes al inicio:

Esto partió como en la época de primavera, se hizo como la Fiesta de la Primavera. $\mathrm{Y}$ entonces, por cursos, se eligieron candidatas, con el objetivo de poder juntar dinero para poder comprar lápices para los niños, comprar cosas para el colegio. [...] Lo que teníamos que hacer era vender votos. $Y$ entonces íbamos donde las instituciones y las instituciones eran nuestros apoderados. Y la que vendía más voto, y era más dinero que entraba para el colegio, era la que ganaba. (Entrevista Jacqueline Rapu Tuki, 2019)

La participación en la Tapati se reviste, en ese relato, con un sentido eminentemente práctico: se trataba, al inicio, de mejorar las condiciones materiales de vida en la isla. Muchas reinas de esta época insisten sobre la precariedad de las condiciones de vida en Rapa Nui, como menciona Erity Teave Hey (2019), Lina Hotu Hey (2020) y Denisse Rapu Tuki (2020). De manera análoga, es posible percibir, en la primera etapa de la Tapati, varios aspectos que remiten a una figura de la reina tal como se hacía en el conti (termino rapanui que refiere al Chile continental) al mismo momento. Esa influencia no sigue una trayectoria lineal, sino que tiene una intensidad variable según las épocas.

Durante el período de la dictadura cívico-militar (1973-1989), las instituciones públicas y estatales (policía, marina y otras) cobran mayor peso, aspecto mencionado en entrevistas por Ema Tuki (2020), Claudia González Pakarati (2020), Jimena Roe Pate (2020) y María Dolores Tuki Pate (2020). Se hacen más presentes características de la celebración vinculadas a una expresión festiva de la "chilenidad". Así, durante varias ediciones, se realizó un "baile de gala" como apertura en el hotel Hanga Roa, donde se presentaba a las candidatas (La Tercera, 18 de enero, 1982; Las Últimas Noticias, 30 de enero, 1984).

Otro elemento llamativo es la insistencia respecto de la reina como avatar de un "progreso" para la isla. En el período 1976-1983, donde se ve también un retorno a la denominación "Fiesta de la Primavera", la reina cobra un papel de agente de la caridad, mediante la realización de visitas y distribución de regalos en el hospital y la cárcel (El Mercurio, 20 de enero, 1976; El Mercurio, 31 de enero, 1981; La Tercera, 18 de enero, 1982). Estos elementos dibujan una reina asociada con la maternidad, lo que remite también a tropos chilenos sobre el sentido de la elección. Esta influencia se materializa, ante todo, a través de una simbología y una estética, persistente durante varios años, que retoma códigos de la fiesta santiaguina. Esta estética fue observada a través de fotos de antiguas Tapati que provienen del archivo fotográfico del MAPSE y de colecciones personales de las reinas, de las cuales seleccionamos dos (Imágenes 1 \& 2). 
Imagen 1. Coronación de Rosa Avaka Tuki (1984).

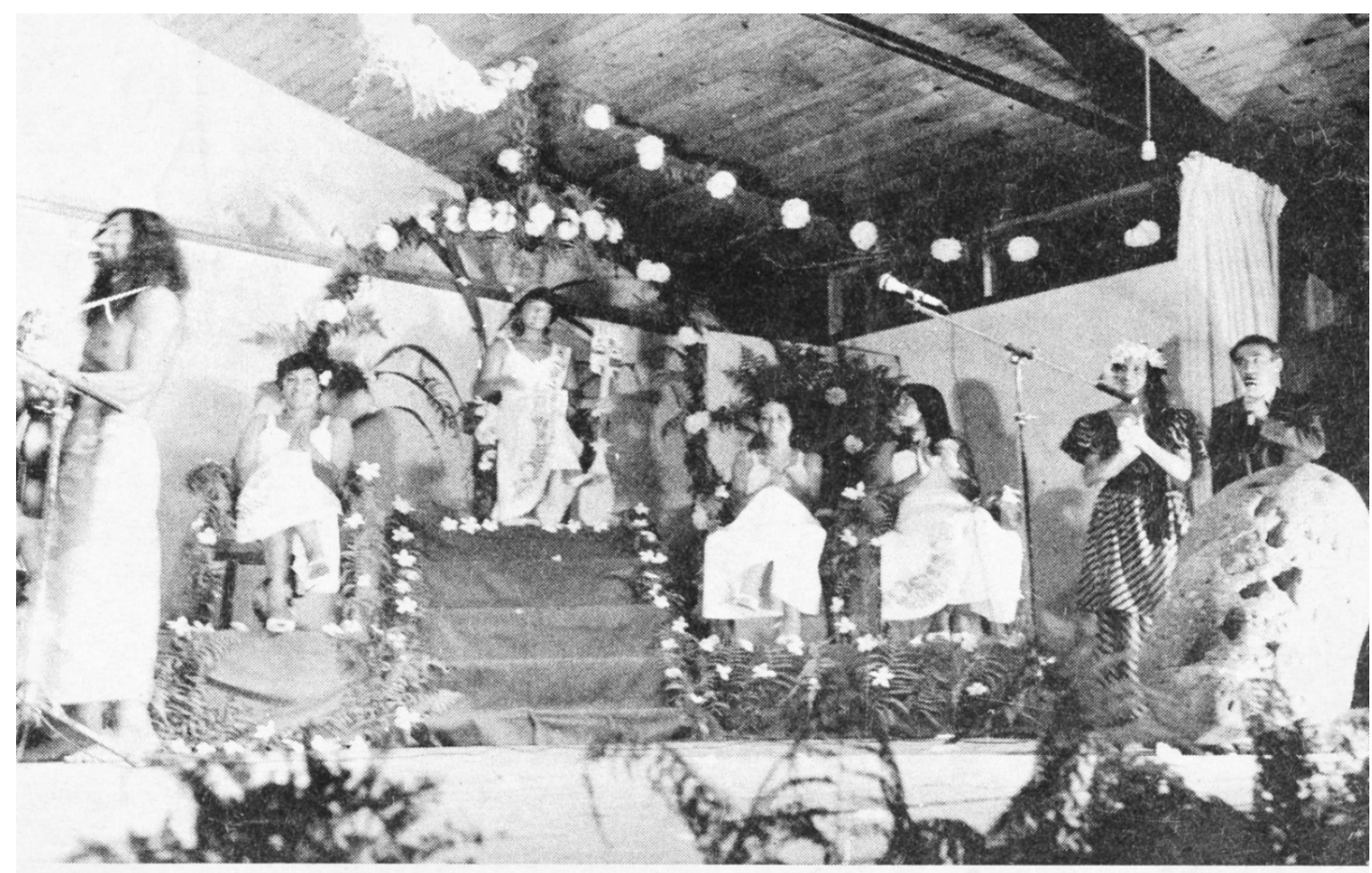

Rosita Avaka assise sur son trône de reine.

Biblioteca William Mulloy, MAPSE.

La primera foto, de la Tapati 1984, nos muestra un escenario construido bajo la forma de la "corte de amor", con una disposición piramidal que sitúa a la reina, en su trono decorado con flores, encima de sus contrincantes. La segunda imagen muestra el escenario de la coronación de María Dolores "Lolita" Tuki Paté, en el gimnasio Koro Paina Kori, durante la Tapati 1986. Al igual que en la imagen anterior, vemos la presencia de flores, de guirnaldas y el predominio del color blanco. Atrás, tenemos paneles pintados con iconografía tradicional (figuras ronorono, manutara, makemake), lo que da cuenta de un sistema estético dinámico, ya en movimiento hacia un sistema étnico-estético (es decir un sistema de imágenes y símbolos asociado a una identidad étnica). 
Imagen 2. Coronación de María Dolores "Lolita” Tuki Pate (1986).

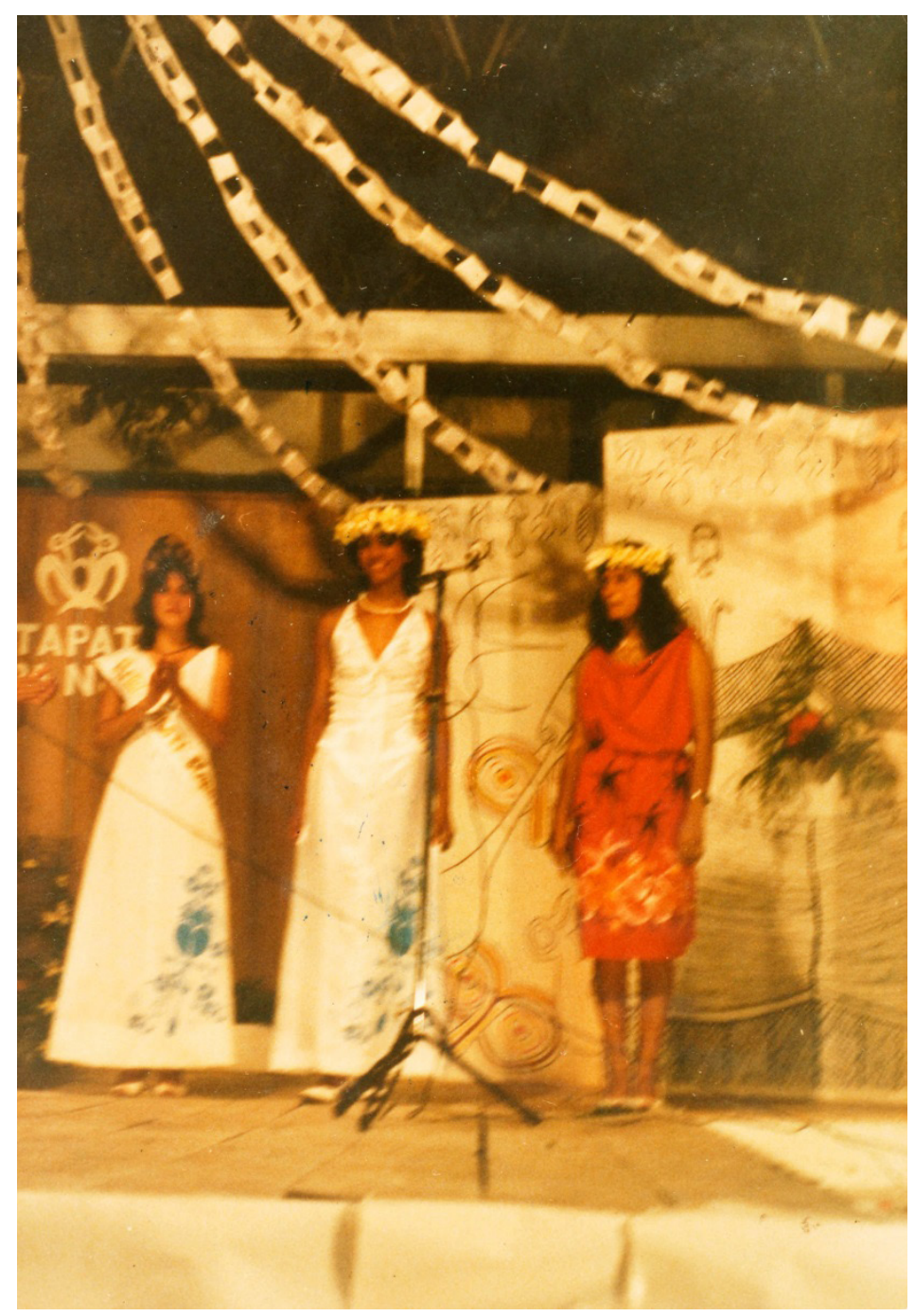

Biblioteca William Mulloy, MAPSE.

Efectivamente, estos rasgos, también presentes en la Fiesta de la Primavera de Chile continental, van disminuyendo con los años. La estética, inspirada en un imaginario romántico de la Antigüedad occidental, cede el paso a una puesta en escena rapanuizada ${ }^{10}$. Al sobreponer la misión de representación y encarnación de una identidad rapanui, también se reformula una gran parte de la construcción genérica de la reina. Esta se edifica en un "diálogo" entre el modelo continental chileno, que va atenuándose, y una "rapanuidad" que irrumpe, visible en los cambios mencionados antes en la candidatura y la elección. La rapanuización ${ }^{11}$ de la fiesta corresponde, por ende, a una rapanuización de la reina, con lo cual se introduce una 
figura forastera en un proceso de apropiación creativa. Con cambios notables en la participación y la estética, la reina se diferencia de la figura continental.

Sin embargo, estos cambios en la "construcción estética de la identidad" (Celigueta, 2017, p. 30) esconden una continuidad en la implicación de la reina en mecanismos de la comunidad rapanui, como el trabajo colectivo - umana- y la competencia -'a 'ati-, nociones que detallaremos más adelante. La implicación en estos mecanismos muestra que la adscripción identitaria trabajada por la Tapati, no solo se define a través de una postura y una apariencia, sino también de un modo de ser y de actuar, un condensado de prácticas y maneras específicas, presentes y vigentes en toda la trayectoria de la figura.

\section{Trabajo colectivo ('umana): la candidata como punto centrípeto}

En el transcurso del período de preparación, la reina debe asumir el rol de congregar el intenso esfuerzo productivo de su alianza. Ella reúne a "su gente", a las personas que van a competir por ella. La alianza así constituida debe operar en los distintos dominios exigidos por la Tapati. Se deben preparar los bailes y cantos, y entrenar para los deportes. Por otra parte, la preparación incluye la confección de trajes ${ }^{12}$, la realización de carros y la planificación de la logística. Si el(la) apoderado(a) se encarga principalmente de esta labor, la candidata tiene un papel "diplomático" y "organizacional".

La alianza se basa mayoritariamente en la hua'ai, o "familia extendida". Se trata del grupo de parentesco no nuclear, que funciona como unidad de reciprocidad (Muñoz, 2014). Es decir, que el apellido, o la pertenencia formal, son indicadores, pero no son suficientes: se necesitan también lazos de solidaridad. En este contexto, la candidata tiene la responsabilidad de circular constantemente de hare en hare ("de casa en casa"), para incentivar, confirmar y reforzar el compromiso hecho, además de vigilar el buen desarrollo de las diferentes obras.

Así, Waitiare Kaltenneger explica que, durante la preparación, su trabajo tuvo que ver con asumir la parte "comunicacional". Con los desplazamientos desde su "cuarto general" (muy a menudo, el hare de los padres o de la(el) apoderada(o)) hasta los otros lugares de la preparación, la candidata asegura el vínculo entre los diferentes elementos de la alianza. Esto la sitúa en el centro del 'umana que se realiza durante la Tapati. El 'umana se define como un trabajo comunitario, colectivo, que implica una reciprocidad. Es también un modo productivo destinado a circular según las necesidades, una cadena de don/contra-don que puede eventualmente ir más allá de la hua'ai. Antiguamente, el 'umana se efectuaba para la construcción de casas o trabajos agrícolas. La familia venía a ayudar y los receptores del 'umana proveían a los participantes con comida (un curanto, llamado umu pare haona). Luego, ese grupo podía ser movilizado para otros trabajos.

Tales elementos se encuentran aún en la preparación de la fiesta. Esta práctica no se realiza mediante un intercambio monetario y hoy en día muchos(as) rapanui la consideran en peligro, por el carácter mercantil que ha ido adquiriendo cada vez más la Tapati (su metalización), lo que refleja el creciente peso alcanzado por el dinero en esta esfera. Esa dimensión "orgánica" (Entrevista Ema Tuki, 2020) quedó destacada en todas las entrevistas que 
sostuvimos con las ariki Tapati. De lo anterior se desprende la idea que lo "fuerte" de una candidatura no se definiría solamente por la persona en sí, sino que integraría el ser rapanui en todas sus facetas, especialmente en su pertenencia familiar y clánica. En última instancia, la fuerza de una candidata dependerá de su capacidad de movilizar dentro de su hua'ai y sus amistades.

\section{Competencia ('a'ati): la candidata dentro de las divisiones de la isla.}

"O la Tapati te une a tu familia, o te separas de ella". (Entrevista Ana Manina Avaka Teao, 2020)

El esfuerzo productivo de alianza, realizado por la candidata, se materializa en una confrontación con otro esfuerzo colectivo, es decir, mediante una competencia en la cual se presenta su candidatura y la de la(s) otra(s) participantes. Competencia, juego y trabajo comunitario tienen una imbricación profunda en la cultura rapanui y son dimensiones que se encuentran expresadas de manera indisociable en la Tapati. Como se expuso anteriormente, al centro del 'umana se encuentra la alianza, construida sobre la hua'ai. Del mismo modo, la forma y la fuerza que tomará la competencia dependerá de cuán reñido sea el enfrentamiento de los dos esfuerzos colectivos. Una candidatura "fuerte", que agrupa a una alianza completa y extendida, frente a otra familia también considerada "fuerte" en el tema cultural, desembocará sistemáticamente en una Tapati con amplia dedicación, participación de la comunidad y con un posible antagonismo agudizado.

Desde ahí, el trabajo colectivo y la competencia se estructuran con base en el parentesco rapanui, que se vuelve determinante al momento de elegir un bando. La regla aquí es que la pertenencia a un mismo grupo de parentesco obliga a comprometerse con ese bando. Con algunos matices, pues siempre quedan márgenes de autonomía para los sujetos: "Si es tu amiga desde que tú vas en el kinder [educación preescolar], ya, voy a hacer competencias para ella en esto, pero tú siempre tienes que dar las competencias más fuertes para la familia..." (Entrevista Waitiare Kaltnegger Icka, 2018).

A la inversa, la pertenencia familiar puede a veces complicar el compromiso con un bando. Como es costumbre escucharlo, "en la isla todos son familiares", y las redes de parentesco pueden ser movilizadas desde varios lados. Por lo tanto, puede ocurrir que una familia sea solicitada en nombre de una filiación común por varias candidatas el mismo año, lo que puede generar grandes tensiones. Ana Manina Avaka Teao (2020) cuenta que tuvo una ventaja durante su candidatura en 1995, gracias a la cercanía familiar de sus dos contrincantes, lo que provocó que "se dividiera la familia". Estos casos de conflictos de lealtad pueden, en los casos más extremos, llegar al abandono de una candidatura, como sucedió en 2020. Una candidata decidió "bajarse", cumpliendo con los deseos de una abuela que no quería ver dividirse a su familia, vinculada a dos candidaturas.

En resumen, a través de la competencia se "cuentan", se evalúan y se refuerzan los lazos dentro la familia: ausencias, presencias y apoyos son remarcados ${ }^{13}$, tanto por la familia como por la candidata/reina, a través de sus intervenciones públicas y discursos. Profundizando ese punto, podríamos decir que la competición tiene como principal "razón de ser" demostrar el funcionamiento y la fuerza del hua'ai. La competencia divide la isla, pero actúa 
también, paradójicamente, como motor de unión al nivel de las familias. Ello puede comprobarse en el énfasis que ponen las reinas en la dimensión colectiva de sus victorias. En eso se expresa una visión del conflicto no solo como un factor de desagregación social y división, sino también de construcción de una unidad conceptual y práctica entre los grupos (Simmel, 1995) ${ }^{14}$. Se trata de un movimiento dialéctico entre "producción de unidad cultural y fraccionismo", elemento ya percibido por Teilhet-Fisk (1996) en el caso de las elecciones de reinas en Tonga (p. 191), un ejemplo "lateral" interesante por su proximidad relativa con nuestro caso.

\section{Reciente variación de la competencia}

Durante la existencia de la Tapati, la forma de la competencia entre candidatas ha mostrado una dinámica de cambio significativa. Estas transformaciones se observan principalmente en la sucesiva reducción del número de candidatas que "se suben" cada año (Gráfico 1). Este fenómeno se da en paralelo con un aumento significativo de la población isleña ( $y$, por ende, del número de candidatas potenciales), la cual pasó de 1.600 habitantes en 1970 a 3.791 en 2012. Proponemos que "el peso" creciente de la candidatura redujo el número de candidatas. Dos factores pueden explicar eso: el cambio del dispositivo de la Tapati y del modo electivo de la reina; y el aumento del tamaño de la Tapati y de los recursos necesarios, especialmente financieros (la metalización).

Gráfico 1. Número de candidatas y reinas por año.

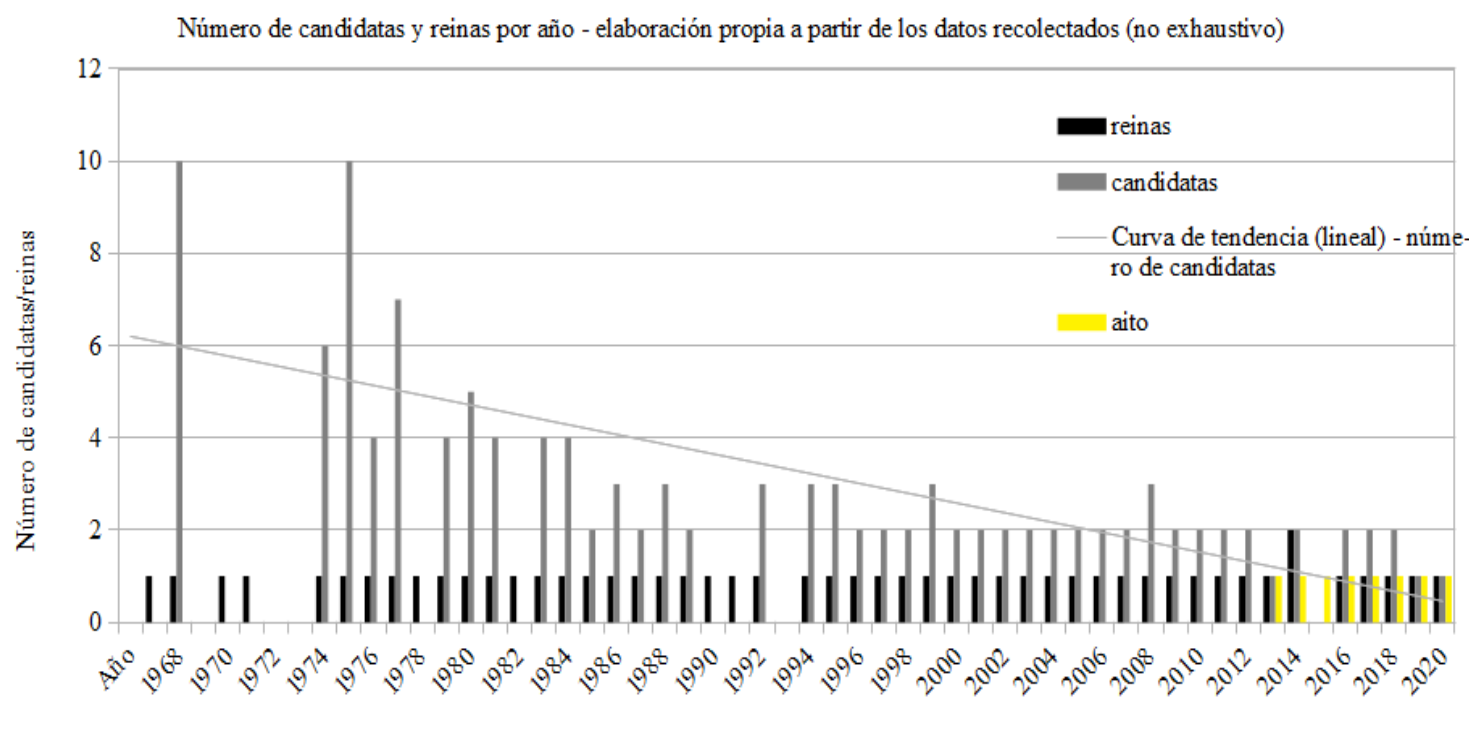

Año

Elaboración propia. 
Con la aceleración de la "rapanuización" de la Tapati y los cambios impulsados por Rodrigo Paoa, la competencia se volvió determinante en la elección y reemplazó, de a poco, la venta de votos, la cual desapareció en los años dos mil. Para estructurar aún más la elección, se decidió dividir, en 1985, la isla en dos lados, Hanga Roa y Moeroa, división que se superpone con el sistema de alianza, lo que deja solamente a dos candidatas para la competición. Esta división apareció tempranamente en la historia poscontacto de la isla, cuando se puso fin a la ocupación del espacio por linaje y se empezó a concentrar la población isleña en el poblado de Hanga Roa, a fines del siglo XIX (McCall, 1976).

Moeroa es la zona barrial ubicada al sur de Hanga Roa, el principal centro habitado, bordeada por Mataveri (donde se encuentran o se encontraban la casa de Percy Edmunds, antiguo administrador de la CEDIP; las oficinas de carabineros y de la Policía de Investigación, etc.). La separación Moeroa/Hanga Roa se vuelve también una separación deportiva (de fútbol, sobre todo) y, en menor medida, familiar. Después de la instauración de este sistema dual, vemos algunas Tapati con tres candidatas, pero parece asentarse la idea de una competencia entre dos alianzas.

A eso se añade la complejidad creciente del proceso de candidatura. Desde los años dos mil, la candidata y el(la) apoderado(a) se ven obligados(as) a firmar un compromiso escrito que asegura la participación de la candidata, salvo situaciones excepcionales. Con el crecimiento de su tamaño, fama y rentabilidad, la Tapati se ha vuelto un imperativo para la Municipalidad, la que busca premunirse de una anulación. Al mismo tiempo, y con el mismo objetivo, se abren las bases (reglamento para los punteos) y el jurado a la coconstrucción y negociación con los apoderados, con el afán de evitar conflictos posteriores. De esta forma, la candidatura resulta ser un proceso que se piensa, se organiza y que toma tiempo.

La otra explicación fuerte a la variación notable de candidatas es el peso financiero. En las conversaciones aparece que son muchas las personas que descartan una posible candidatura de una hija, sobrina o nieta por la inversión considerable que representa. Se produce, por ende, una exclusión de las familias más modestas de la competencia por la corona, mientras que otras se endeudan. La Municipalidad entrega una suma de varios millones de pesos a las familias participantes. Según la opinión de varias reinas entrevistadas, esta contribución sigue siendo insuficiente para cubrir todos los gastos. En eso vemos también la inflación de la Tapati, pues el aumento de los conjuntos, carros y pruebas, además de su espectacularización, va de par con un incremento del precio asumido por las instituciones, las familias y la candidata.

Ahora bien, algunos textos explican también el actual sistema dual desde la perspectiva de la cosmovisión bipartida polinésica (Andrade, 2004). Podría ser un "ajustamiento" conceptual expos, pero nos parece que las explicaciones de la configuración tienen que ver, más bien, con problemáticas concretas y un sentido práctico.

Los elementos precedentes nos orientaron hacia la conformación de un dispositivo festivo complejo, donde la participación en la Tapati se convierte, al mismo tiempo, en una meta financiera y en "el juego del honor" (Entrevista Juliette Hotus, 2018). En los últimos años, el dispositivo se ha vuelto inestable, con una competencia 
insegura. En 2013, por primera vez en la Tapati, surgió una candidatura única (de Ma’Eha León Durán). Si bien la postulante no tiene claridad sobre la ausencia de contrincante, podemos avanzar que su candidatura, preparada desde un largo tiempo, desalentó a otras de lanzarse. Ese año apareció un competidor hombre para sostener la Tapati junto a Ma’Eha León Durán. La Municipalidad organizó una competencia de deportes y destreza entre Hopu Manu (término que designaba a los competidores en la antigua ceremonia del Tanata Manu).

En 2014 se repitió esta modalidad y en 2015 no se presentó ninguna reina. A partir de ese momento se implementó el aito ${ }^{15}$, que en tahitiano significa "persona valiente, con coraje" (Muñoz, 2017), para acompañar a la candidata, con el objetivo principal de repartir el peso de la corona entre dos familias (Entrevista Juliette Hotus, 2018) y asegurar una mayor estabilidad a la competencia y la fiesta. Pero no todos(as) concuerdan en que el aito sea algo positivo. Si algunas reinas pueden llegar a concederle la misma importancia que a su propio papel (lo cual no es el caso hasta ahora), otras lo consideran "innecesario", porque, al final, "la corona es una sola". También subrayan que el aito puede complejizar las cosas para la candidatura y que no todas las uka y familias pueden encontrar un aito. Implica más personas en el complejo juego de lealtades y obligaciones recíprocas, lo que conlleva el riesgo de producir intersecciones en el interior de la misma familia (Entrevista Ana Manina Avaka Teao, 2020).

La última variación en la competencia de reina fue la candidatura única en 2019 y 2020, que surge como el encuentro entre una ausencia de candidaturas y una reorientación estratégica del dispositivo por parte de la Municipalidad.
No más competencia entre dos alianzas: la Tapati se hace con una candidata, con competición individual en deportes y artesanía, y de "conjuntos" en bailes y canto. La idea es de contraponer la figura de la reina a las fuerzas centrífugas que sacuden a la comunidad.

Esta nueva configuración divide: varias personas deploran la ausencia de competencia, diciendo que el festival Tapati se vuelve fome (aburrido), mientras otras valoran la unión así materializada de la comunidad (Entrevista Lina Hotus Hey, 2020; Entrevista Erity Teave Hey, 2019). Lo anterior desemboca en una situación compleja, ya que la competición es vista, a la vez, como motor de movilización de las personas y factor de división y conflictos innecesarios. Favorece la participación en las alianzas, pero simultáneamente desestabiliza el dispositivo entero cuando el "precio" (material y simbólico) de la derrota es demasiado alto para motivar a la familia a involucrarse.

Una corona para articular la isla: representantes, emprendedoras y embajadoras

\section{Hacer el "interfaz" con el turista: negociar con visitantes e imaginarios}

"La Tapati se ofrece como un espejo hacia el pasado, al igual que como la instancia que posibilita su apropiación, convirtiéndose simultáneamente en un espacio híbrido" (Delsing, 2017, p. 215). En esa fórmula, Riet Delsing pone el acento en el papel de interfaz que tiene la Tapati entre diferentes espacios, dimensión también subrayada por Dan Bendrups (2008). A través de ella se establece un canal entre diferentes tiempos, pues proyecta elementos del pasado histórico (construyendo lo auténtico) 
en un presente a través de performances. Esta situación de brecha en la cual se encuentra la Tapati es similar a la de otras elecciones: brecha entre la definición de una identidad cultural y otros asuntos de política local y translocal (Bellerino et al., 1996). Es por esa condición que a veces encontramos elementos contradictorios en el papel de la reina. Ella formula, a la vez, un discurso hacia la comunidad y hacia el exterior, el cual se presenta principalmente mediante la figura del turista. En cuanto a la estética, ya vimos las formas contradictorias que se dieron, por ejemplo, entre el traje tradicional y el traje de gala, que coexistieron en una misma celebración.

Con todo, la trayectoria histórica de la Tapati muestra un cambio neto hacia una manera de presentar las performances como elementos tradicionales para asegurar el control de la producción cultural, como ha sucedido en otras elecciones (Celigueta, 2017). Al mismo tiempo que se desarrolla un "hacer cultura" específico, se opera una mercantilización de esa cultura (Delsing, 2017). Ese doble movimiento, entre construcción de lo étnico y mercantilización de sus manifestaciones, fue planteado por varios autores en otros contextos (Comaroff \& Comaroff, 2009).

En este caso, ha sido inevitable el cruce, en la figura de la reina, de diferentes influencias y misiones. Desde las primeras candidatas y reinas, que recibían a los pasajeros que venían a ver la Tapati, al aeropuerto, son perceptibles los fenómenos de promoción del turismo. También vemos aflorar imaginarios exóticos, sensuales y sexuales sobre los(as) isleños(as) $y$, a fortiori, sobre la reina, en cuanto a su particular y visible estatuto de figura femenina. Estos imaginarios no nacen con la Tapati, solo retumban en la fiesta. Se presentan como la continuidad de la construcción occidental de una Polinesia sensual y atractiva (y de manera implícita sexualmente disponible) que remite a antiguas construcciones coloniales, adoptadas por Chile (Muñoz, 2017). En los relatos comunicados por la prensa nacional chilena sobre la elección de la Tapati se transparenta, en la imagen que se dibuja de la reina, la exotización y sexualización de la mujer rapanui. Por ejemplo, las candidatas "muestran toda la belleza de las mujeres pascuenses" (La Tercera, 30 de enero, 1995), mientras que sus retratos, en traje de baño, asocian mujeres y paisajes en un solo marco idílico.

Con la asimilación de la Tapati a un concurso de belleza, aparecen varios "desentendimientos" sobre el sentido de la festividad y la corona. De ello resulta una relación compleja y ambigua entre las reinas y la belleza como criterio para la elección:

\begin{abstract}
No es un tema de belleza, sino que es un tema de... Bueno, aparte de la belleza, la gente igual busca una belleza... La que quiere entrar puede ser linda, fea, pues no sé, pero aquí lo importante son tus conocimientos. ¡No saco nada con ser hermosa, subirme al escenario y decir cualquier tontería!. (Entrevista Taurama Hey Rapu, 2018)
\end{abstract}

Además, se esperan ciertas conductas y comportamientos de la reina, los cuales están relacionados con un registro estereotipado, no específico a la Tapati, y que se expresa, por ejemplo, en la "tiranía de la sonrisa" en un contexto de grabación y evaluación constante de la imagen. Tamy Rapu Atan (ariki Tapati 2006) plantea lo siguiente en una entrevista con la prensa: "Acá llegan estadounidenses, franceses, chinos, japoneses, australianos, chilenos continentales, etc. Nosotras tenemos 
que estar siempre sonriendo, saludando a la gente, estar atentas, y ellos nos corresponden con amabilidad" (Las Últimas Noticias, 1 de febrero, 2006). O también en este relato de Ana Tucki Hucke: "Yo había hecho eventos en el Piriti, acoger los clientes, estar con ellos, ser encantadora con ellos... Había que conquistar a la gente" (Entrevista Ana Tucki Hucke, 2018, traducido del francés).

\section{"Dar a ver" el poder \\ y la identidad rapanui en la Tapati}

Si bien la Tapati no es un evento directamente político, se transforma, a pesar de todo, en una arena política por la convergencia de espacios en un solo momento. Así, la Tapati es la ocasión para varias autoridades de visibilizarse (la Municipalidad, pero también el Consejo de Ancianos en algunas ediciones) con sus discursos, en el clip promocional, etc. La Tapati entrega también un discurso político en su gestión del espacio, con la creación de fronteras espaciales y sociales. Estas "fronteras" internas a la fiesta permiten a la comunidad guardar un control del dispositivo festivo en un contexto de intenso contacto. Vemos, así, que en la Tapati hay accesos diferenciados entre rapanui y no rapanui (a veces llamados "competidores y no competidores" en el contexto de la fiesta) a los diferentes espacios, según su uso y sacralidad.

La candidata y la ariki Tapati también tienen la oportunidad de visibilizar, de "dar a ver" el poder. Al situarse en la brecha entre diferentes mundos, la reina puede indicar una jerarquía entre los diferentes sistemas de valores presentes. Siguiendo el análisis de TeilhetFisk (1996), vemos en la Tapati el uso de un sistema etnoestético, a través de una elección importada, para subrayar la predominancia de los sistemas locales de valores sobre las consideraciones foráneas, encarnadas por el turista. Es decir, que los sentidos y consideraciones rapanui son valorizados sobre otros, pero siempre se hacen concesiones y negociaciones. Este es un motivo recurrente en las entrevistas: si bien nadie niega el peso del turismo, se asegura que "la Tapati es para que [sus] niños tengan el legado, más que para el turista" (Entrevista Lina Hotu Hey, 2020). El encuentro entre el turismo y la elección permite sobreexponer las diferencias en un evento visual, en una puesta en escena de una cultura patrimonializada (Dziubinska, 2017). Las uka y ariki Tapati forman parte del control de la representación y de la producción de artefactos e imágenes culturales: es un control autóctono de la representación, que constituye una arista de la etnicidad rapanui.

Un elemento particularmente significativo al respecto es el idioma. Cuando Nani Tuki Pont, ariki Tapati 2020, se subió en el escenario para la noche de apertura, se dirigió hacia la comunidad mediante un extenso discurso en vānana rapanui. Luego, al momento de dejar el escenario, se dio cuenta que no se había comunicado en español, como es costumbre. Entonces decidió retomar la palabra, disculpándose y justificando que su inadvertencia fue ocasionada por el hecho de tomarse "muy en serio [su] papel de la cultura".

Ese momento da cuenta de los fuertes cambios consecutivos que se han ido dando a través de las sucesivas reinas, como lo muestra la siguiente historia. En 1975, en un contexto tenso, Erity Teave Hey es elegida reina. La dictadura cívico-militar, a pesar de ser bastante invisible desde la isla, prohíbe, a través de un 
decreto de su gobernador (Artn Arietsen) el uso del vānana rapanui, lo que provocó fuertes protestas de los y las habitantes. Justo ese año, en el momento de la Tapati, Pinochet estaba de visita en la isla. Erity, junto con su padre (Juan Teave), solicitó una reunión con Pinochet, en la que le pidieron y consiguieron la anulación del decreto. Ella utilizó su corona con objetivos políticos, un ámbito en el cual Erity Teave seguirá actuando después. Aunque el uso del idioma fue autorizado, reinas ulteriores (como Elena Varas Edmunds) hablaron de la dificultad respecto de la práctica del vānana dado las discriminaciones, la estigmatización y el racismo. A la luz de estos relatos, la actitud de Nani cobra un potente sentido de afirmación y autonomía del poder rapanui, a través de un signo identitario primordial, como lo es el idioma, elemento ya visto por otros autores (Fischer, 2005, p. 257).

La reina actuó más de una vez en ese escenario para simbolizar una gran problemática y explicitar la posición de la comunidad. En 2015, cuando la comunidad decidió cerrar el parque nacional de la isla para protestar contra la explotación por parte de la Corporación Nacional Forestal (CONAF) y el Estado, la siguiente ariki Tapati representó un baile en el que se recordaba esa movilización y ese cierre "con las cuerdas". En una temática similar, el takona de Nani evocó la gran contaminación que hay en la isla, especialmente por el plástico, y llamó al autocuidado rapanui sobre este problema. La representación que hace la reina de la isla y de sus problemáticas, no solo se efectúa durante la Tapati, también se exporta, en especial en el "espacio-hermano" polinésico.

\section{Embajadoras y emprendedoras: las reinas hacia el exterior}

El "protocolo" del viaje hacia el conti es un elemento compartido por gran parte de las reinas y remite a una "proyección" hacia el exterior. La reina, encarnación y "mejor representante" de la comunidad, tiene como misión casi intrínseca salir a representar y ayudar a esta última. De esta manera, establece un papel ascendente que supone obligaciones y que, a la vez, le otorga una posición jerárquica dentro de la comunidad.

La idea que la reina tiene que salir a "probar suerte", para luego regresar con sus logros y ganancias, era un principio bastante fuerte en períodos durante los cuales el aislamiento de la isla era mayor. En aquel entonces, se insistía mucho en la importancia de formar profesionales, con el anhelo que volvieran a la isla después a desarrollar su actividad, además de compartir los recursos con su familia (eso es parte de una estrategia en la cual la isla de esos años quiso fortalecer las conexiones con el conti, por ejemplo, mediante una cierta exogamia). Durante su viaje a Temuco, Inés Paoa Rido, reina 1970, explica: "apenas se me dio la ocasión, retorné a Chile para domiciliarme en Santiago en busca de nuevos horizontes". Hace la promoción del viaje al conti como lleno de promesas:

Inés nos cuenta que lo encontrado en el continente lo desea para todas las jovencitas de su edad que continúan en Pascua. Lo anhela para que completen sus estudios, adquieran otras vivencias y puedan obtener cargos tan bonitos y futuristas como el que ella desempeña en Lan-Chile. (El Austral, 8 de septiembre, 1972) 
Hoy en día, sigue presente la idea del "deber de formación" de las reinas. Así, en un clip de la Tapati 2020, la directora de la película y reina 2018, Waitiare Kaltenegger lka, invita a las jóvenes rapanui a organizarse y cumplir sus sueños, mientras que Hineva Pakarati evoca la idea de una escuela de preparación para las candidaturas. Queda bastante presente el foco dado por muchas candidatas en la educación de los niños y niñas, lo que denota una asociación vigente entre la construcción femenina de la reina y una ética del care, del "cuidado".

Otra faceta de la misma moneda es la misión de embajadora que tiene la reina durante los viajes. Esta se ha hecho presente desde la primera edición, cuando la ariki Tapati va al conti, se hospeda en el hotel Carrera en Santiago, para después desplazarse a La Serena, Viña del Mar y Valparaíso (Ilustre Municipalidad de Isla de Pascua, 2012). En las siguientes ediciones, se convirtió en costumbre viajar por Chile y fue así como algunas reinas lograron cierta fama, como Elena "Makarina" Araki Pakomio, reina 1968, quien fue recibida en varias ocasiones en la Moneda por Allende (Stambuk, 2016). La conexión con el conti se volvía también una ocasión para visibilizar y dar a conocer la precariedad que persistía en la isla.
La ariki Tapati, considerada como el "rostro de la isla", permite, además de propiciar reivindicaciones dirigidas hacia el Estado chileno, trazar, mediante sus viajes internacionales, las fronteras étnicas y sus contenidos para el pueblo rapanui. En ese sentido, el espacio polinésico toma una especial relevancia y mantiene una conexión estrecha desde el inicio de la fiesta. Los rapanui alimentaron una circulación privilegiada con la Polinesia (especialmente la Polinesia francesa) y se posicionaron como nación ma'ohi a través de numerosos vínculos anteriores a la Tapati, que se aceleraron a partir de la segunda mitad del siglo XX. En 1972, una delegación rapanui participó por primera vez en un festival cultural en Nueva Zelandia y en 1975 Rapa Nui entró en la South Pacific Commission, lo que promocionó el intercambio cultural en la zona (Bendrups, 2019, p. 127). Denisse Rapu, reina 1981, tras su victoria, viajó a Tahiti con su madre (Imagen 3). En estos viajes y "giras culturales", las reinas son frecuentemente invitadas por el conjunto que va de gira: "Fuimos a Tahiti. Nosotros llevamos un moai en el colegio de Mahina en Tahiti, en la Polinesia Francesa" (Entrevista Jimena Roe Pate, 2020). 
Imagen 3. "Miss Rapa Nui en vacances". Les Nouvelles, octubre 1981.

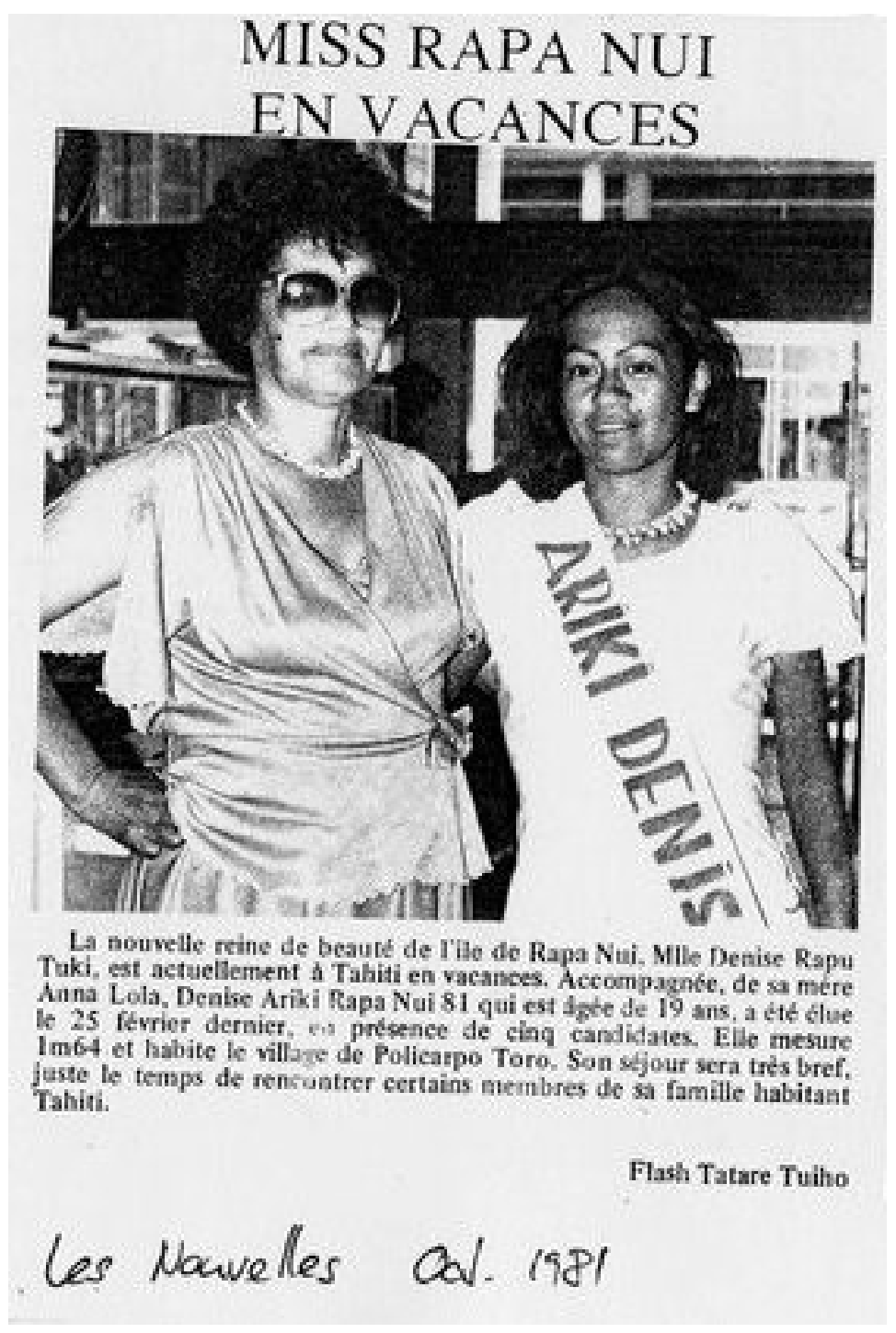

Estos intercambios culturales se mantienen hasta el día de hoy, como lo relata Hineva, ariki Tapati 2019. Durante su reinado, Hineva acompañó, en su calidad de reina, al "súper conjunto" Peu Tupuna ${ }^{16}$ al festival de Taputapuatea en Raiatea, en Polinesia Francesa. Ese festival, llamado también "Los Nueve Tentáculos", celebra las navegaciones y migra- ciones polinésicas (los "tentáculos"). Hineva viajó como ariki Tapati, es decir, con su corona puesta y con una vestimenta diferenciada, un elemento importante en la manifestación de un estatus peculiar. Pudo también intercambiar con otros pueblos polinésicos sobre el sentido de su elección, comparándola con lo que ocurre en otras islas. 
A pesar que existe una profusión de elecciones de reinas en el Pacífico, y que todas tienen como objetivo asentar y discutir contenidos y fronteras identitarias, y también, a veces, asuntos de disidencias y minorías dentro del mismo grupo (Alexeyeff, 2000; Teilhet-Fisk, 1996), pocas protagonizan una elección tan "integral". En Hawai'i, las reinas son, en su mayoría, elegidas por linaje, mientras que en Tahiti son elecciones de "Miss", con criterios de belleza y moda. En Fiji, el certamen del Hibiscus Festival, mencionado por Dan Bendrups como una influencia posible de la Tapati, también se enfoca en la "belleza" de sus postulantes, su postura y actitud (Bendrups, 2019, p. 97; Bossen, 2000). Es decir, que tenemos elecciones que protagonizan reinas-encarnaciones distintas, con criterios muy variables.

Por consiguiente, se inicia un juego sin fin de identificación/diferenciación con el resto de los pueblos polinésicos, que incide, en el contacto, a forjar la identidad rapanui. Así lo expresa Hineva, a propósito de su viaje al festival de Taputapuatea:

Tu Ilegai, y la vibra es otra. Se siente que no es como los otros festivales, ir y bailar no más... Nooo, se siente el mana del lugar. Y la ceremonia es súper fuerte, iponte tú, las mujeres no podemos subir a los ahu, yo siendo reina, no pude subir!. (Entrevista Hineva Pakarati, 2020)

A pesar de estas atribuciones, varias son las que se quedan con las "ganas" de "hacer más". Otras dan cuenta de la dificultad del retorno "a la vida normal", luego de este intenso proceso. En efecto, apareció, en varias entrevistas, cierta nostalgia, un spleen del reinado, de lo efímero de la corona. Esto se debe al carácter de rito de paso que adquiere la Tapati y, por ende, a su finitud. A eso se añade el sentimiento compartido de una desaparición relativa de la reina después de su elección y de un período de reinado que no sería usado como debería (algunas culpan aquí un desinterés de las autoridades y de la Municipalidad en hacer vivir el reinado).

\section{Conclusión}

\section{¿Hacia un estatuto remodelado de la reina?}

Los años 2019 y 2020 se presentan como ediciones "gemelas" con un significado peculiar: en 2019 , la isla atraviesa un período de relativa turbulencia política, entre un conflicto sobre la gestión del parque por parte de la Comunidad Indígena Polinésica Mau Henua y un trágico homicidio, que dejó tensiones y heridas profundas en la comunidad. De esta manera, se decidió posicionar el reinado de Hineva Pakarati, única candidata, bajo el lema de la unión y la harmonía comunitarias (Entrevista Hineva Pakarati, 2019; Entrevista Juliette Hotus, 2020).

Así, la Municipalidad y la comisión Tapati decidieron dedicar la edición a todas las reinas de los años anteriores. Organizaron reuniones con numerosas reinas, se mandaron a realizar nuevas coronas y bandas. Más aún, en 2019 las reinas se subieron al escenario y en 2020 este fue decorado con retratos fotográficos de ellas realizados por la Municipalidad. Finalmente, se realizó una exposición de los retratos al exterior del Centro del Lector Katipare, ubicado en Atamu Tekena, calle principal de Hanga Roa (Imágenes 4 \& 5). De esta manera, diariamente y durante varios meses, al pasar frente al centro, cada rapanui y visitante pudo apreciar estos rostros, no hechos de piedra basáltica, pero que encarnan una parte de la historia contemporánea de la isla. 
Imagen 4. Los retratos fotográficos de las ariki Tapati en el Centro del Lector.

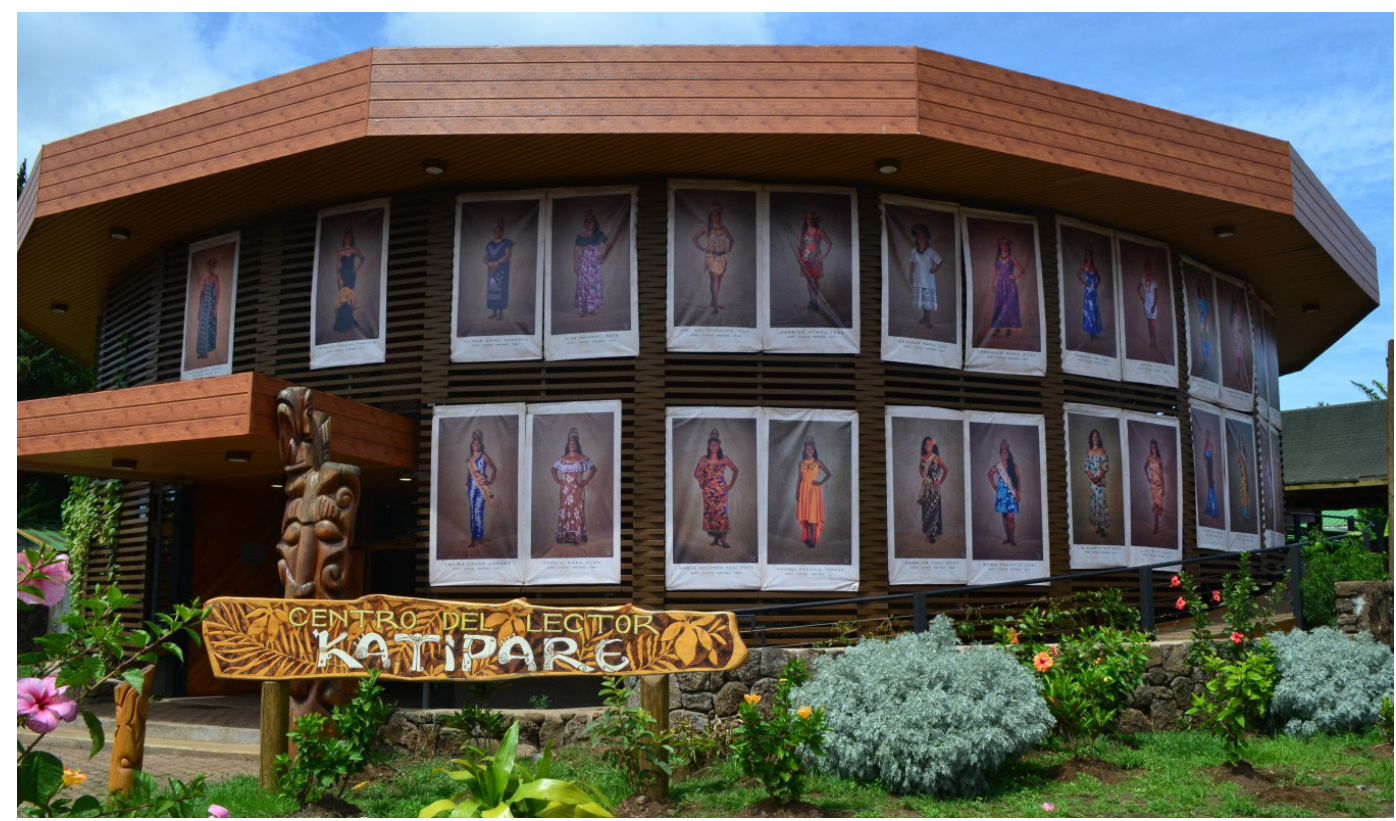

Fotografía del autor.

Imagen 5. Ceremonia de apertura de la Tapati 2020, con la ariki Nani y el aito Pio en medio del escenario dedicado a las ariki.

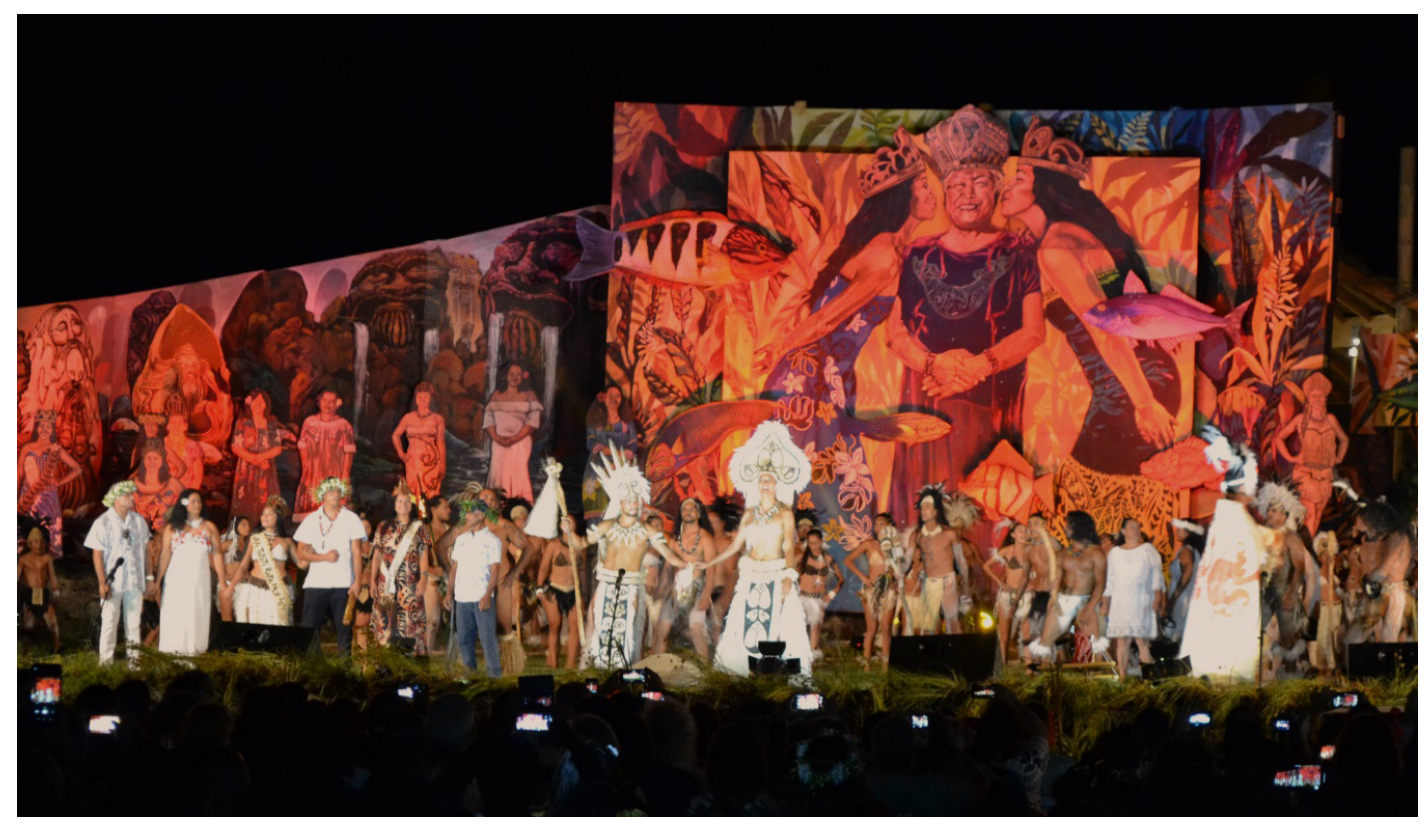

Fotografía del autor. 
Con estas ediciones en que se desarrolla una candidatura única, aparece una nueva configuración de la ariki no solamente como un rostro juvenil, destinado a ceder su lugar a otro más juvenil al año siguiente, sino como un título que otorga un estatus durable. En las dos últimas ediciones se materializó una peana común a todas las reinas, donde además de compartir el escenario en 2019, tuvieron la oportunidad de transmitirse entre ellas sus distintas vivencias.

A través de esa base experiencial y emocional común, se quiso borrar las diferencias para subrayar un estatuto común, aunque el hecho de ser reina no suplanta otras afiliaciones políticas o familiares, más esenciales. Se quiso, sin embargo, realzar el objetivo trascendental a todas: "obrar por la cultura" ("la verdadera Reina”, entrevista Erity Teave Hey, 2019), bajo el entendimiento de la "cultura" como parte integrante y no separable del "ser rapanui".

Esa operación municipal fue, sobre todo, una oficialización de lo que ya existía en la población rapanui. Siempre ha habido reinas que fueron recordadas con cariño por sus aliados y aliadas de aquel entonces ("todavía algunos me llaman ariki y me saludan así en la calle"). Estas lealtades forjadas a través del trabajo común crean las bases de solidaridad que resuenan en las Tapati siguientes. Las reinas son elementos de esa cadena de la reciprocidad, verdadero corazón de la Tapati. Fabrican un cemento emocional entre sus participantes, con sus victorias y derrotas.

\section{Consideraciones finales}

Hemos enfatizado en la subsunción de la corona a lo colectivo, en particular en la fase de la candidatura, lo cual marca una gran diferencia con otras elecciones. Del dispositivo de la Tapati nace una reina-encarnación estrechamente dependiente de unidades sociales englobantes. Se trata también de una corona que descansa en una persona y que, por lo tanto, está sujeta al uso y sentido dado por la reina ${ }^{17}$. Cada encarnación sucesiva de la ariki Tapati modela un poco la corona y su sentido (se podría hablar de agentividad frente a la elección). Lo anterior se percibe también a través de las diversas experiencias, posiciones y opiniones que hemos presentado a lo largo de este artículo. Cada reina pudo hacer un uso estratégico de su corona, en proyectos personales (y a veces profesionales).

Para concluir, la reina atestigua de los usos cambiantes que se pueden dar de un dispositivo festivo: la construcción de una figura que resuena, por un lado, bajo una condición de "chilenidad" y, por el otro, con una rearticulación que modifica la figura de la reina para expresar una identidad cultural rapanui. Los cambios en la corona muestran a una reina que tiene como propósito formular respuestas a problemáticas propias de la comunidad, lo que hace de ella una figura contextual y dinámica, escrita a varias voces. Ese dinamismo entre diferentes "secuencias", que tienen una relativa de sucesión cronológica, se encuentra visibilizado en los relatos.

Si bien hubo cambios, la corona se caracteriza también por haber sido siempre la encarnación de un esfuerzo colectivo y familiar, en competencia con otro. Entre rupturas y constancia, la figura de la reina es testigo, entre otros, de la capacidad rapanui de combatir el colonialismo hasta en sus emanaciones festivas, lo cual es un vector poderoso en el caso de Chile. Basta pensar en el cortejo de celebraciones cívicas, 
de "inventos de tradiciones" que efectuó y efectúa Chile (Hobsbawm \& Ranger, 2012; Valenzuela, 2014). La capacidad del pueblo rapanui para usar una plataforma foránea y reformularla con el fin de priorizar una definición local de la corona, da cuenta de una perspectiva de autonomía siempre presente.

\section{Agradecimientos}

Quisiera agradecer a la comunidad, y a todas las reinas y candidatas que me ofrecieron conversar y me permitieron adentrarme en sus historias y sus Tapati. Espero haber sido fiel a sus vivencias y experiencias. En el orden cronológico: Erity Teave Hey, Jacqueline Rapu Tuki, Ana Tucki Hucke, Beatriz Marina Tuki, Lina Hotu Hey, Denisse Rapu Tuki, Elena Angélica Varas Edmunds, María Dolores "Lolita" Tuki Pate, Claudia González Pakarati, Emma Tuki, Jimena Roe Pate, Ana Manina Avaka Teao, Vanessa Natalia Teao Pakarati, Tamy Rapu

\section{Notas}

\footnotetext{
${ }^{1}$ Se designa así al espacio de migración, intercambio y de relativa unidad cultural conformado por Nueva Zelandia (Aotearoa) en el suroeste, Hawai'i en el norte y Rapa Nui en el este.

${ }^{2}$ El término ariki designa a los antiguos jefes rapanui, que cumplían roles rituales y políticos y poseían mana.

${ }^{3}$ La noción de "dispositivo" que usamos está basado en el concepto de Giorgio Agamben, quien lo construyó sobre la definición dada por Foucault. Podríamos definir el dispositivo como la red entre diversos elementos, leyes, discursos, instituciones... Es "lo que remite a una economía, es decir a un conjunto de praxis, saberes, medidas, instituciones, cuyo objetivo es gestionar, gobernar, controlar, orientar, en un sentido que se quiere útil, los comportamientos, los gestos y los pensamientos de los humanos" (Agamben, 2006, p. 6). Desde ese punto de vista, la elección de reina es un "dispositivo festivo", pues realiza una gestión y orientación de prácticas y discursos a través de la vía festiva. El dispositivo es una noción interesante porque permite pensar un sujeto (en el sentido múltiple de esa palabra) "actuado" por un dispositivo, pero también "actuante", capaz de subvertir y resignificar.
}

Atan, Lucy Alejandra Haoa Tuki, Ma’Eha León Durán, Taurama Hey Rapu, Waitiare Kaltnegger Ika e Hineva Pakarati.

\section{Muchas gracias al Museo Antropológico Padre} Sebastián Englert y en especial al equipo de la biblioteca William Mulloy, a la Comisión Tapati y a la Comisión Reina de la Municipalidad por su disponibilidad y su constante ayuda. Agradecer también a profesores(as) y colegas que en la isla o afuera me ayudaron a la construcción y la corrección de mi reflexión (mi directora Jimena Obregón Iturra, el profesor Héctor Morales y mis queridas colegas Josefina Arriagada, Mélanie Lercier y Célia Merdji), así como al Comité Editorial de la revista.

Un especial agradecimiento a la familia Tuki Rengifo. A Etu'u, Tukura y toda la familia Tuki Arránguiz por acogerme siempre con una increíble gentileza: māuru'uru, les estoy eternamente agradecido.

\footnotetext{
${ }^{4}$ La Compañía Explotadora de Isla de Pascua, o Compañía "Williamson-Balfour", era la empresa ovejera a cargo de la isla durante toda la primera mitad del siglo XX.

${ }^{5}$ En 1964, la ONU puso en marcha un protocolo de descolonización frente al cual Chile se vio obligado a clarificar la naturaleza de su relación con la isla. Al mismo tiempo, se levantó el secreto sobre las condiciones de vida de sus habitantes tras la difusión de testimonios de rapanui en el país. Para más información, ver Foerster \& Moreno, 2016.

${ }^{6}$ En 2018, las dos candidatas, Vaitiare Rapu Merino y Waitiare Kaltnegger Icka, tienen una edad más avanzada, cosa que destacaron como una ventaja: "Porque todos los años, son de 18 años [las $u k a]$, cuando recién salen del colegio y piensan todavía en qué van a estudiar... Esta vez, la idea de la Tapati era: mujeres ya con su profesión, ya con su misión, ya con su experiencia, con todo para apoyar a la cultura [...]" (Entrevista Waitiare Kaltnegger Icka, 2018).

${ }^{7}$ Es interesante destacar la repartición genérica entre empresariadohombre/beneficencia-mujer, un motivo recurrente en las fiestas con reinas.
} 
${ }^{8}$ Entre los deportes/actividades tradicionales introducidos en estos años encontramos: Moa Pakeopa (tallado de la piedra), Mata Moru (buceo con lanza), 'a'ati Hoi (caballo), Hoa Pou (deslizamiento en tronco), 'a'ati Kau (natación), Hoa miro ki runga o te tumu maika (lanzamiento de jabalina al tronco de un plátano), Pei Amo (Haka Pei) deslizamiento con takona, Tau'a Rapa Nui pa ari, Rapa Nui tau re’a re'a (triatlón senior \& juvenil).

${ }^{9}$ Sobre ese vínculo entre la representación, la performance y la actualización de la vigencia de los mitos en las sociedades polinésicas y rapanui, ver Andrade, 2004; Arthur de la Maza, 2009; Sahlins, 1985.

${ }^{10}$ Ese cambio se hace paulatinamente mediante la influencia de conjuntos folklóricos como Tu'u Hotu Iti. Creada en 1975, esta agrupación abre la vía a la teatralización de las leyendas, cuentos, historias de la isla y al reúso de la vestimenta tradicional, tanto del mahute (fibras vegetales) como el hami. sobre la pasarella"ina,familialilial, en competencia con otroaber sido una encaranci

${ }^{11}$ Ese concepto de rapanuización fue utilizado por Pablo Andueza para hablar del fenómeno de participación intensa de la etnia rapanui en la vida institucional chilena a partir de los años sesenta. Esta participación se dobla con una interpenetración entre el sistema político rapanui y el continental. Ver Andueza, 2000.

${ }^{12}$ La confección de trajes se volvió, en los últimos quince años de Tapati, un trabajo colosal debido al número creciente de competidores. En 1995, Ana Manina Avaka Teao cuenta que los conjuntos se

\section{Referencias bibliográficas}

Agamben, G. (2006). Théorie des dispositifs. Po\&sie, 1(115), 25-33. doi: 10.3917/poesi.115.0025.

Alexeyeff, K. (2000). Dragging drag: The performance of gender and sexuality in the Cook Islands. The Australian Journal of Anthropology, 11(2), 297-307. doi: 10.1080/00664677.2016.1150808

Andrade, P. (2004). Artífices del imaginario: La puesta en escena, una aproximación a la construcción de identidad Rapa Nui. (Tesis inédita de maestría). Universidad Academia de Humanismo Cristiano, Santiago.

Andueza, P. (2000). Hacia el reconocimiento de los derechos políticos de los pueblos originarios: El modelo de cogestión en Isla de Pascua. Estudios Atacameños, (19), 113-120. doi: 10.22199/ S07181043.2000.0019.00006

Arthur de la Maza, J. (2009). Hakari o te Rapa Nui: Representación del mito en Rapa Nui: De ritual ancestral a performance postmoderna. Cátedra de Artes-Pontificia Universidad Católica de Chile, (7), 65-92.

Barth, F. (1976). Los grupos étnicos y sus fronteras: La organización social de las diferencias culturales. México: Fundo de Cultura Económica.

Bellerino, C., Wilk, R. \& Stoeltje, B. (Eds.). (1996). Beauty limitaban a 15-20 bailarines. En los últimos años, estos llegan fácilmente a más de 200 personas. La búsqueda de los materiales (plumas) se extiende más allá del territorio insular, movilizando a redes translocales.

13 "iLa tía no fue a ayudar ni una vez con las sopaipillas!"o "Gracias taina por haber estado presente con nosotros" son frases que es común escuchar durante la preparación de una Tapati.

${ }^{14}$ Parece importante subrayar ese punto en el contexto de Rapa Nui, donde son numerosas las teorías que describen un colapso generalizado en la isla debido a una competencia aguda por los recursos y conflictos incesantes. Hoy en día, varios estudios refutan esa visión de una isla atrapada en una competencia mortífera, mostrando, al contrario, mecanismos de cooperación y adaptación.

${ }^{15}$ Encontramos en los años anteriores una figura un poco similar con el "Hombre diez", ganador del decatlón, prueba maestra durante la Tapati de inicios de los años ochenta (Entrevista Ema Tuki, 2020). Esa afiliación al deporte queda vigente con el aito, quien se encarga a menudo de congregar a los deportistas, otra repartición genérica visible de los papeles dentro de la Tapati.

${ }^{16}$ Peu Tupuna es una agrupación que congrega a miembros de varios conjuntos de la isla. Su actual director es Lynn Rapu.

${ }^{17}$ Ese uso individual se encuentra, quizás, favorecido por la penetración de consideraciones vinculada a un individualismo capitalista, donde la corona es un elemento que se puede "valorizar" en una óptica personal y profesional.

queens on the global stage: Gender, contests and power. Nueva York: Routledge.

Bendrups, D. (2008). Pacific festivals as dynamic contact zones: The case of Tapati Rapa Nui. Shima: The International Journal of Research into Island Cultures, 2(1), 14.

(2019). Singing and survival: The music of Easter Island. Nueva York: Oxford University Press.

Bossen, C. (2000). Festival Mania, tourism and nation building in Fij: The case of the Hibiscus Festival, 1956-1970. The Contemporary Pacific, 12, 123-154. https://doi.org/10.1353/cp.2000.0006

Celigueta, G. (2017). ¿Unas elecciones de verdad?: Autenticidad, representación y conflicto en los concursos de Reinas Indígenas de Guatemala. Journal de la société des américanistes, 103(1), 27-49.

Comaroff, J. \& Comaroff, J. (2009). Ethnicity, Inc. Chicago: The University of Chicago Press.

Comisión Verdad Histórica y Nuevo Trato con los Pueblos Indígenas. (2008). Informe de la Comisión Verdad Histórica y Nuevo Trato con los Pueblos Indígenas. [Informe gubernamental]. Comisionado Presidencial para Asuntos Indígenas, Santiago.

Concha, R. (2017). Dinámica del turismo y transformaciones 
en los usos del patrimonio en la Isla de Pascua. (Tesis inédita de doctorado). Universitat de Barcelona, Barcelona.

Delsing, R. (2017). Articulando Rapa Nui: Políticas culturales polinésicas frente al Estado chileno. Santiago: LOM.

Deshoullière, G. \& Dziubinska, M. H. (2017). Des Miss à part : Les concours de beauté au prisme des différences en Amérique latine. Journal de la société des américanistes, 103(1), 13-26.

Dziubinska, M. H. (2017, febrero 13). Les concours de beauté amérindiens. Nouvelles formes de spectacularisation de l'indianité. Nuevo Mundo, Mundos Nuevos. Conferencia llevado a cabo en el congreso final ANR FABRIQ'AM La fabrique des patrimoines dans les Amériques indiennes aujourd'hui, Paris.

El Austral (1972). Joven pascuense de paso en Temuco. 8 de septiembre.

EI Mercurio (1976). Semana de Rapa Nui se inició en Pascua. 20 de enero.

(1981). Celebración de la "Semana Rapa Nui". 31 de enero.

Englert, S. (1974). La Tierra de Hotu Matu'a: Historia y etnología de la Isla de Pascua Santiago: Universidad de Chile.

Espinosa, F. (2013). "Para engrandecer el alma, fortalecer el espíritu y afrontar con mayor seguridad el porvenir". Fiesta de la Primavera y orden social en la zona central de Chile, 1940-1950. En Seminario Simon Collier 2012 (pp. 13-43). Santiago: Instituto de Historia, Pontificia Universidad Católica de Chile, Ril. Recuperado de http://historia.uc.cl/images/stories/seminario/simon_collier_2012.pdf.

Fernández, A. \& Venegas, L. (2010). Fiesta, identidad y estrategias de una minoría que se organiza: La reina de las flores de una comunidad latina en Texas. Migraciones Internacionales, 5(3), 113-142. Recuperado de http://www.scielo.org.mx/scielo.php?script=sci_ arttext\&pid=S1665-89062010000100004\&Ing=es\&tIng=es

Fischer, S. R. (2005). Island at the end of the world. The turbulent history of Easter Island. Londres: Reaktion Books.

Foerster, R. \& Moreno, C. (2016). More Manava. 'OAnata ararua ko Porofe ( $2^{\mathrm{a}}$ ed.). Rapa Nui: Rapanui Press.

Hobsbawm, E. \& Ranger, T. (2012). L'invention de la tradition. París: Amsterdam.

Ilustre Municipalidad de Isla de Pascua. (1990). Guía del visitante. Ilustre Municipalidad de Isla de Pascua, Biblioteca William Mulloy.

(2012). Guía del visitante. Ilustre Municipalidad de Isla de Pascua, Biblioteca William Mulloy.

La Tercera (1982). Hasta los moais bailarán durante semana pascuense. 18 de enero.

(1995). Carmela, la última reina pascuense. 30 de enero.

Las Últimas Noticias (1984). En el "ombligo del mundo" tampoco escapan los festivales. 30 de enero.

(2006). Tami Rapu, candidata en la fiesta "Tapati": "Ser reina de Isla de Pascua es algo súper grande". 1 de febrero.

Luz Hurtado, M. de la (2008). La performance de los Juegos Florales de 1914 y la inadecuada presencia de Gabriel Mistral en ellos. Revista Chilena de Literatura, (72), 163-191.

McCall, G. (1998). Rapanui: Tradición y sobrevivencia en Isla de Pascua. California: Easter Island Foundation.

(1976). Reaction to disaster: Continuity and change in Rapanui social organisation (Tesis inédita de doctorado en filosofía). The Australian National University, Canberra.

Métraux, A. (1941). Ethnologie de l'île de Pâques. París: Gallimard.

Muñoz, D. (2014). Kinship predicaments in Rapa Nui (Easter Island): Autochthony, foreign and substantial identities. Rapa Nui Journal, Easter Island Foundation, (28), 25-34.

(2017). Diaspora Rapanui (1871-2015): L'île de Pâques, le Chili continental et la Polynésie française: Une ethnographie historique de la mobilité dans une société transnationale. (Tesis inédita de doctorado). École des Hautes Etudes en Sciences Sociales, Marsella.

Pakarati, F. (2016). Costumbres y vivencias en Rapa Nui. Rapa Nui: Rapanui Press.

Sahlins, M. (1985). Islands of history. Chicago: University of Chicago Press.

Simmel, G. (1995). Le conflit. París: Circé.

Stambuk, P. (2016). lorana \& goodbye: Una base yanqui en Rapa Nui. Santiago: Pehuén.

Stoeltje, B. (1996). The snake charmer queen : Ritual competition, and signification in American Fest. En Bellerino, C., Wilk, R. \& Stoeltje, B. (Eds.), Beauty queens on the global stage: Gender, contests and power (pp. 13-29). Nueva York: Routledge.

Teilhet-Fisk, J. (1996). The Miss Heilala beauty pageant: Where beauty is more than skin deep. En Bellerino, C., Wilk, R. \& Stoeltje, B. (Eds.), Beauty queens on the global stage: Gender, contests and power (pp. 185-202). Nueva York: Routledge.

Valenzuela, J. (2014). Fiesta, rito y política: Del Chile borbónico al republicano. Santiago: Dirección de Bibliotecas, Archivos y Museos. 